\title{
Numerical modelling of the slurry flow in pipelines and prediction of flow regimes
}

\author{
M. Swamy, N. González Díez \& A. Twerda \\ Heat Transfer and Fluid Dynamics, Technical Sciences, \\ TNO, The Netherlands
}

\begin{abstract}
Large scale numerical modelling of slurry flow in horizontal pipelines has been carried out. A combination of analytical and commercial CFD modelling, with Eulerian two-phase flow models, has been used in the present investigation. The modelling results are validated with well-documented experimental data and are found to be in good agreement. Flow regime maps were developed and pressure drops calculated for a wide range of flow rates, particle sizes and solid concentrations. It was observed that flow regime maps calculated with analytical empirical correlations near the transition flow regimes are unreliable. It is concluded that the performance of this model at the presented scales allows for application at smaller scales that still feature turbulent flows.

Keywords: slurry flow, CFD, Eulerian model, volumetric concentration, flow regime, pressure drop.
\end{abstract}

\section{Introduction}

Transportation of solid particles in the form of slurry through pipelines has become widespread in recent years. Principal applications include the transportation of metal concentrate and tailings, coal, sand, chemicals and minerals which involve several industrial sectors, such as chemical processing, mining and mineral processing, deep see mining, dredging, coal, and oil sand. This mode of transport has grown in recent years since it has proved to be attractive compared with alternatives such as road, rail, shipping and air freight. Different mechanisms are active in the solid-liquid mixture flow, and numerous empirical models have been developed to describe the mechanisms governing the slurry flow regimes [1-3]. In general, slurry flow regimes can be divided into 
homogenous, heterogeneous, moving bed, stationary bed and saltation. The most common slurry flow is the heterogeneous flow regime, in which turbulent suspension and inter-granular contact are two significant mechanisms of particle transport. Clogging or plugging of the pipe is undesirable for the safe operation of the process and can lead to slurry hammer. To avoid this situation, the liquidsolid mixture velocity in the pipeline is kept much higher than the critical deposition velocity. There is always a trade-off between the slurry velocity and pressure drop in the system. Accurate identification of slurry flow regimes and prediction of the pressure drop still remain a challenge.

Computational Fluid Dynamics (CFD) has been increasingly used to investigate a variety of multiphase fluid flow problems. One advantage of the CFD approach is that 3-D solid-liquid flow problems under a wide range of flow conditions and flow regimes can be rapidly evaluated, which is almost impossible experimentally. There are relatively few studies [4-8] using CFD to model the slurry flow to predict flow patterns and pressure drop for fine particles.

Therefore, detailed numerical work on the pressure drops and flow regimes for larger particles at higher solid concentrations is needed. The present numerical investigation is motivated by a need to provide more understanding on slurry flow in a horizontal pipeline and to characterise the flow regimes based on the parametric range of interest by the designers. Given the range of parameters and limited amount of time, experimental studies are impractical. Given the reliability of CFD simulations for steady multiphase flows, a systematic numerical study has been conducted to understand the flow patterns and related phenomena in a horizontal pipeline.

An extensive literature review [4, 9-12] of the experimental work on slurry flow relevant to industrial applications such as chemical process, dredging and mineral processing industries has been carried out. The work of Matousek [9] and Kaushal et al. [4] contains extensive information for the wide range of parameters of interest. These [4,9] have been used for the validation of numerical results.

In the next section, the mathematical modelling used in the numerical simulations such as model equations, geometry and grid, boundary conditions and numerical solution are discussed. This is followed by the results, including a discussion of the parametric studies and validation of simulation results. The flow regime prediction by empirical equations and CFD calculations is discussed in the subsequent section. Finally, the major conclusions are presented.

\section{Mathematical modelling}

\subsection{Numerical methodology}

The Eulerian-granular multiphase flow model has been used in the present study. The Eulerian model solves momentum and continuity equations for each phase. Coupling between the phases is implemented through the pressure and interphase exchange coefficients. In this model, the different phases are treated as inter- 
penetrating continua [8]. In the case of granular flows, these equations are closed by application of granular kinetic theory. It has been shown that the Euleriangranular multiphase model gives better results $[4,14]$ compared with the other multiphase models. The $k-\varepsilon$ turbulence model with standard wall functions and mixture turbulence model is used. Granular phase modelling involves defining the granular temperature by applying the algebraic model of Syamlal et al. [13]. Granular viscosity and bulk viscosities are modelled by applying the model of Syamlal et al. and Lun et al. [13]. The Syamlal-O'Brien drag model [13] is used. Lift forces and turbulent dispersion are neglected.

\subsection{Geometry and grid}

The length and inner diameter of the horizontal pipeline are based on two validation cases. For the validation with Matousek [9], a pipe length of $3 \mathrm{~m}$ and pipe diameter of $150 \mathrm{~mm}$ was used. For the validation with Kaushal et al. [4], a pipe length of $3 \mathrm{~m}$ and diameter of $50 \mathrm{~mm}$ was used. A multi-block structure, non-uniform grid system with hexahedral cells was used to discretise the computational domain. The computational grid for this pipeline consists of 450,000 elements.

\subsection{Boundary conditions}

The calculation domain for the horizontal pipe is bounded by the inlet, the wall and the outlet boundaries. For the single phase flow (water) simulations, uniform velocity profile at the inlet and pressure at the outlet boundary are applied, whereas the respective boundaries for the multiphase flow simulations are a fully developed velocity profile at the inlet and pressure at the outlet. Uniform solid volumetric concentration is applied at the inlet boundary. A no-slip boundary condition is imposed on the wall and heat transfer is not considered. Investigations carried out are shown in Table 1.

Table 1: Geometrical and flow conditions for the simulations.

\begin{tabular}{|l|c|c|c|c|}
\hline Validation & $\begin{array}{c}\text { Pipe } \\
\text { size, } \mathrm{D} \\
{[\mathrm{mm}]}\end{array}$ & $\begin{array}{c}\text { Inlet } \\
\text { velocity, } \\
\mathrm{V}_{\mathrm{m}}[\mathrm{m} / \mathrm{s}]\end{array}$ & $\begin{array}{c}\text { Particle } \\
\text { size, } \mathrm{d}_{50} \\
{[\mathrm{~mm}]}\end{array}$ & $\begin{array}{c}\text { Solid volumetric } \\
\text { concentrations, } \\
\mathrm{V}_{\text {fin }}[\mathrm{v} / \mathrm{v}]\end{array}$ \\
\hline Matousek [9] & 150 & $2-6$ & $0.075-1.85$ & $0.12-0.43$ \\
\hline Kaushal et al. $[4]$ & 50 & $2-6$ & 0.125 & $0.3-0.5$ \\
\hline
\end{tabular}

Water (density $\rho_{1}=1000 \mathrm{~kg} / \mathrm{m}^{3}$ and dynamic viscosity $\mu_{1}=0.001 \mathrm{~Pa} \mathrm{~s}$ ) is used as the liquid phase and sand (density $\rho_{\mathrm{s}}=2500 \mathrm{~kg} / \mathrm{m}^{3}$ ) is used as the solid.

\subsection{Numerical solution}

The CFD solver, ANSYS Fluent 14.5.7, is used in the numerical investigation of solid-liquid flow. For the slurry flow through the horizontal pipe, steady state simulations were performed. The second order upwind discretization scheme is selected for solving the momentum, turbulent kinetic energy, and turbulent 
dissipation energy, while first order upwind discretisation is used for solving the volume fraction equation.

The convergence criterion is based on the residual value of the calculated variables, such as mass, velocity components, volume fraction, turbulent kinetic energies and turbulent dissipation rate. In the present simulations, the residual reduction factor $10^{-4}$ for each variable was used to monitor the convergence of the iterative scheme. A Linux cluster machine with 4 processors was used for the parallel computing.

\section{Results and discussion}

\subsection{Validation of numerical results}

Numerical modelling results are validated with the experimental data of Matousek [9] and Kaushal et al. [4].

In the experiments $[4,9]$, the local mixture density in the pipeline crosssection was measured by a radiation density meter. In the vertical direction across the pipeline cross-section, the chord-averaged mixture density was measured. It was then converted to values of local spatial volumetric concentration of solids. Following these two experimentalists, we used a similar technique to calculate the spatial volumetric solid concentration in the spatial direction $(\mathrm{y} / \mathrm{D}$, where $\mathrm{y}$ is the height from the pipe centre and $\mathrm{D}$ is the diameter of the pipe). The chord-averaged solid volumetric concentration (see Figure 1(b)) is calculated as

$$
\mathrm{Cv}(\mathrm{y} / \mathrm{D})=\frac{1}{2 \mathrm{x}} \int_{-\mathrm{x}}^{\mathrm{x}} \mathrm{C}(\mathrm{x}, \mathrm{y} / \mathrm{D}) \mathrm{dx}
$$

where $\mathrm{Cv}$ is the chord-averaged volumetric concentration at any point in the vertical direction of pipe, $C$ is the spatial volumetric concentration and $x$ refers to the horizontal or lateral position.

Comparison of the CFD-predicted and experimental data of Matousek [9] for two particle sizes with different solid volumetric concentrations $\left(\mathrm{d}_{50}\right.$ of $0.12 \mathrm{~mm}$ with $V_{\text {fin }}$ of $34 \%$ and $d_{50}$ of $0.37 \mathrm{~mm}$ with $V_{\text {fin }}$ of $24 \%$ ) is shown Figure 1 . There is good agreement between numerical predictions and experiments for both particle sizes. The discrepancy between the predictions and experiments for the $0.37 \mathrm{~mm}$ particle size could be due to the spread in the particle size used in the experiments (though the mean particle size is $0.37 \mathrm{~mm}$ ). The slurry flow regime seems to be heterogeneous suspension (asymmetric) for both cases.

The predicted pressure gradients are presented in the form of dimensionless hydraulic losses [9]. The dimensionless hydraulic losses are calculated as

$$
\mathrm{I}_{\mathrm{m}}=\frac{\Delta \mathrm{P}_{\mathrm{m}}}{\rho_{\mathrm{l}} \mathrm{gL}}
$$

where $\Delta P_{m}$ is the slurry mixture pressure drop in the pipe and $L$ is the pipe length.

The predicted dimensionless hydraulic losses calculated using equation (2) are compared with the experimental data of Matousek [9] with different solid volumetric concentrations, mixture velocities and particle sizes (as shown in 
Figure 2). There is very good agreement between the measurements and the CFD calculated data. It is observed that, with a reduction in the mixture velocity, there is a decrease in the hydraulic loss. Pressure drop decreases non-linearly with the decrease in the mixture velocities.

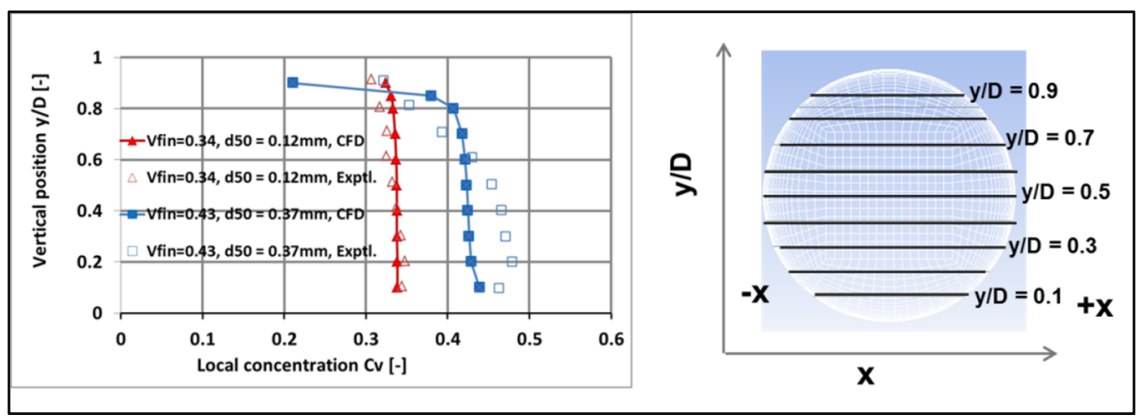

Figure 1: Comparison of predicted solid volumetric concentration with the Matousek [9] and chord averaged measurement at the pipe crosssection.

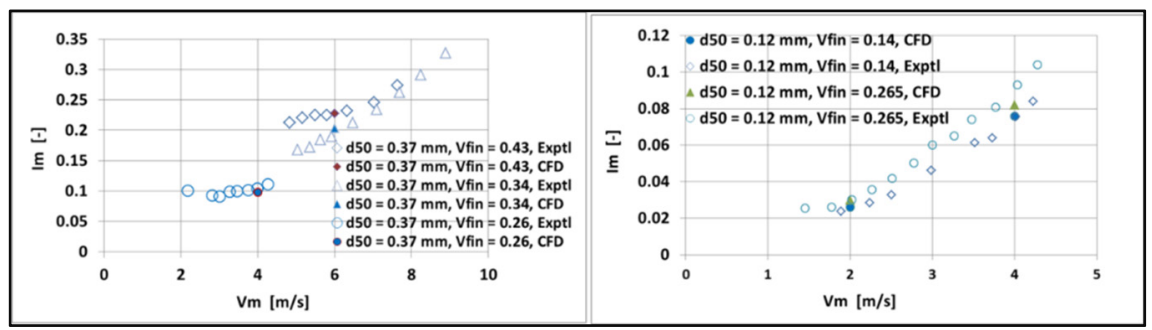

Figure 2: Comparison of dimensionless hydraulic losses between the experimental data [9] for two particle sizes.

Validation of numerical results with the experimental data of Kaushal et al. [4] is shown in Figure 3. Comparison of solid volumetric concentration is based on the $\mathrm{V}_{\text {fin }}$ of $30 \%$ and a mixture velocity of $4 \mathrm{~m} / \mathrm{s}$. There is good agreement between the CFD prediction and experimental data. CFD predicts a lower concentration than the experiments only in the upper section of the pipe crosssection. The flow regime based on the prediction is heterogeneous. Similarly, comparison of slurry mixture pressure gradients $\left(\Delta \mathrm{P}_{\mathrm{m}} / \mathrm{L}\right)$ between the CFD predicted and experimental data are also shown in Figure 3. Pressure gradient varies non-linearly with the flow rate.

\subsection{Parametric studies}

The effect of particle size, mixture velocity and solid volumetric concentrations on the flow patterns, pressure drop and flow regimes are explained below. 

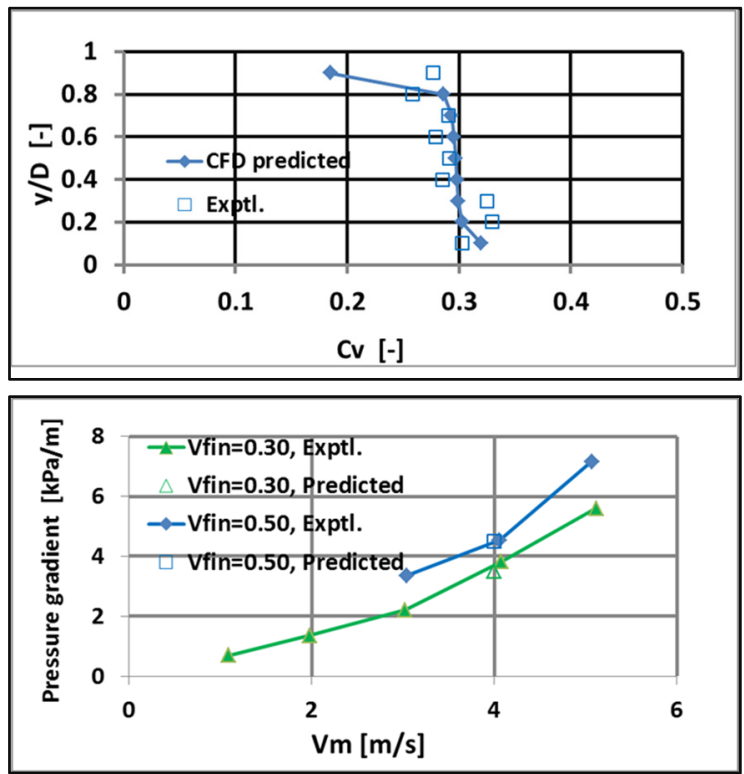

Figure 3: Comparison of solid volumetric concentration and pressure gradient between the predicted and experimental data [4].

The effect of particle size on the local solid concentrations for inlet $V_{\text {fin }}$ of $0.34[\mathrm{v} / \mathrm{v}]$ and $\mathrm{V}_{\mathrm{m}}$ of $4 \mathrm{~m} / \mathrm{s}$ is shown in Figure 4 . For smaller particles, local concentration is very close to the mean and as the particle size increases, deviation of local $\mathrm{Cv}$ from the mean value also increases. The flow regime changes from almost homogenous $\left(\mathrm{d}_{50}<0.12 \mathrm{~mm}\right)$ to heterogeneous $\left(\mathrm{d}_{50}=0.37\right.$ $\mathrm{mm})$ or moving bed regime $\left(\mathrm{d}_{50}>0.74 \mathrm{~mm}\right)$. This can be due to greater hindrance of the settling of larger particles. For the larger particles, gravitational force becomes important. The solid phase volumetric concentration for $\mathrm{d}_{50}$ of $1.85 \mathrm{~mm}$ and $\mathrm{V}_{\mathrm{m}}$ of $4 \mathrm{~m} / \mathrm{s}$ at three different locations along the pipe length (inlet, centre and near the outlet of the pipe) is shown in Figure 5.

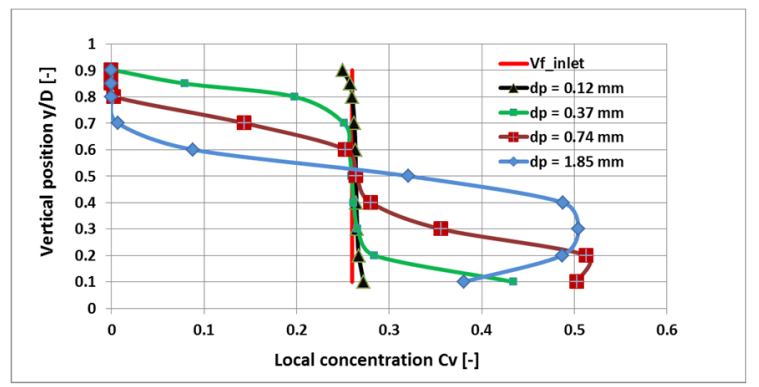

Figure 4: Solid concentration profiles for different particle sizes. 


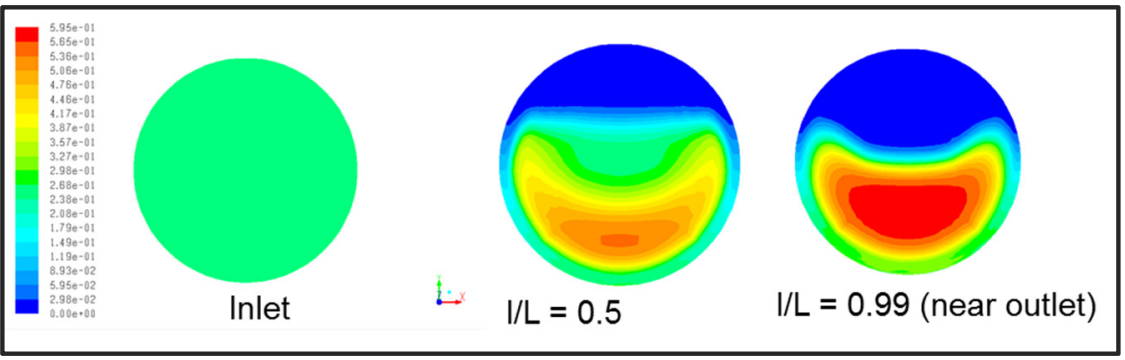

Figure 5: Solid phase volumetric concentrations at the inlet, in the middle and near the outlet pipe cross-sections for $\mathrm{d}_{50}=1.85 \mathrm{~mm}$.

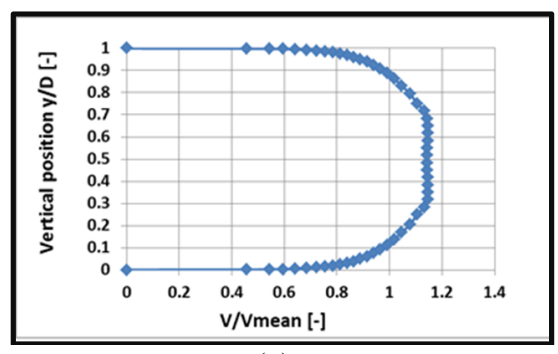

(a)

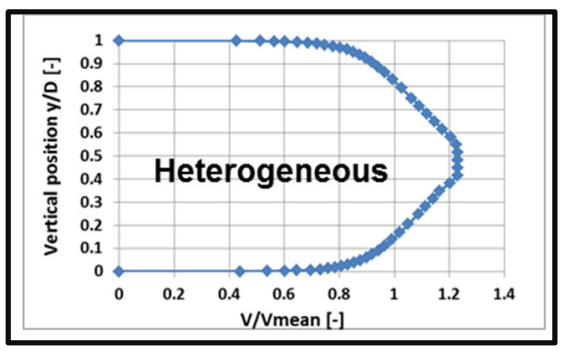

(b)

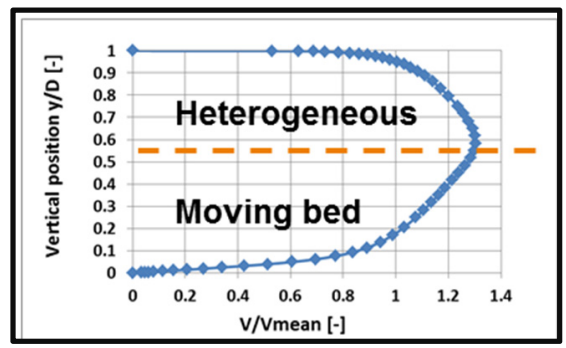

(c)

Figure 6: Velocity profiles near the outlet: (a) single phase (b) multiphase $\mathrm{d}_{50}=0.12 \mathrm{~mm}$ and (c) multiphase $\mathrm{d}_{50}=1.85 \mathrm{~mm}$.

The water velocity profile along the height of the pipe near the outlet for single phase water, and multiphase with $\mathrm{d}_{50}$ of $0.12 \mathrm{~mm}$ and $1.85 \mathrm{~mm}$ is presented in Figure 6. It is observed that for the larger particles, the lower section of the pipe shows low velocities which could be due to the moving bed formation. The upper section of the pipe still exhibits the heterogeneous flow regime.

The effect of mixture velocity on the local solid concentration across the pipe is shown in Figure 7. The results are based on particle size of $0.37 \mathrm{~mm}$ and $26 \% \mathrm{v} / \mathrm{v}$ solid concentration at the inlet. It is observed that for the lower mixture velocity the concentration is more heterogeneous. It indicates that the gravitational force of the particles starts to dominate. 


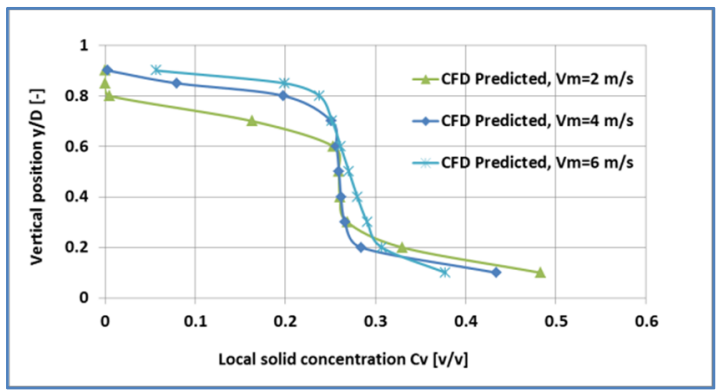

Figure 7: Solid concentration profiles for different mixture velocities.

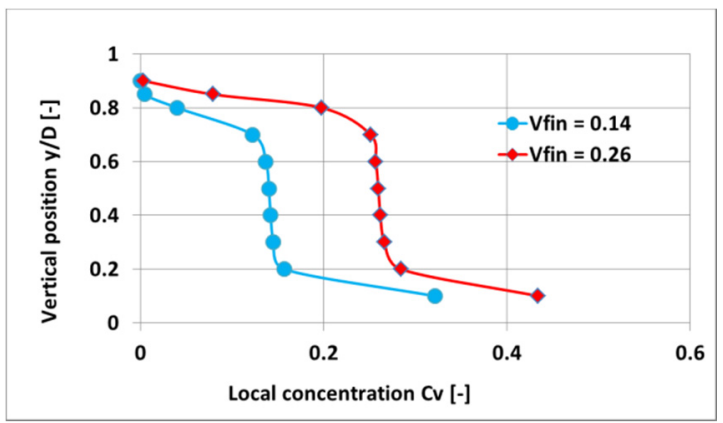

Figure 8: Solid concentration profiles for different inlet solid volumetric concentrations.

The effect of inlet solid volumetric concentrations is shown in Figure 8. These are based on a particle size of $0.37 \mathrm{~mm}$ and $\mathrm{V}_{\mathrm{m}}$ of $4 \mathrm{~m} / \mathrm{s}$. Higher inlet concentrations result in higher concentration at a given vertical height in the pipe. The flow regime for either case is heterogeneous suspension. Particles start to settle.

Dimensionless hydraulic losses calculated using equation (2) for all the simulated cases is shown in Figure 9. It is observed that particle size has a significant impact on the pressure losses. Solid volumetric concentration has less effect on the pressure losses for smaller particles.

\subsection{Slurry flow regimes}

This section briefly describes flow regimes predicted with empirical models and predicted by CFD calculations.

Various names have been given to the transition velocity at which slurry flow regimes change, such as critical/threshold velocity or deposition velocity. Empirical correlations can be used, for given physical properties, to calculate the transition velocity. This provides a good indication of the flow regime at any given velocity but can be unreliable near the transition regime. 


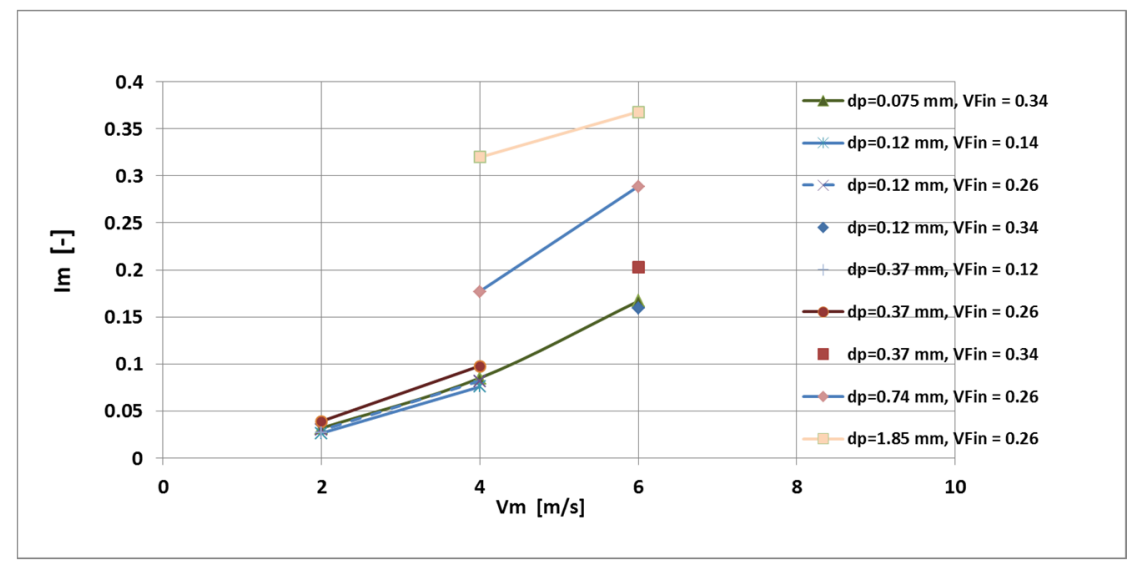

Figure 9: Hydraulic pressure gradient for different cases.

\subsubsection{Stationary bed to moving bed}

The transition between the stationary bed and moving bed flow regime is related to the critical friction velocity. It is given by

$$
\begin{gathered}
\mathrm{V}_{2}=\mathrm{u}_{\mathrm{c}}^{*}\left(\frac{2}{\mathrm{f}_{\mathrm{m}}}\right)^{0.5} \\
\mathrm{u}_{\mathrm{c}}^{*}=\sqrt{\frac{\mathrm{Fr}_{\mathrm{crt}}^{\prime}\left(\rho_{\mathrm{s}}-\rho_{\mathrm{l}}\right) \mathrm{gd}_{\mathrm{p}}}{\rho_{\mathrm{l}}},}, \\
\mathrm{Ar}=\frac{\left(\rho_{\mathrm{s}}-\rho_{\mathrm{l}}\right) \mathrm{gd}_{\mathrm{p}}^{3}}{\rho \vartheta^{2}}
\end{gathered}
$$

and

$$
F r_{d}=\frac{v_{l}^{2} \rho_{l}}{\left(\rho_{s^{-}} \rho_{l}\right) g d}
$$

$u_{c}^{*}$ is the critical friction velocity and is calculated from the critical densimetric Froude number $\left(\mathrm{Fr}^{\prime}{ }_{\mathrm{crt}}\right) . \rho_{\mathrm{s}}, \rho_{\mathrm{l}}, g, d_{p}$ are solid density, liquid density, gravitational constant and particle diameter respectively. The $\mathrm{Fr}_{\text {crt }}$ is estimated [15] from Figure 10 for a given an Archimedes number (Ar). $f_{m}$ is a constant and is assumed to be 0.005 .

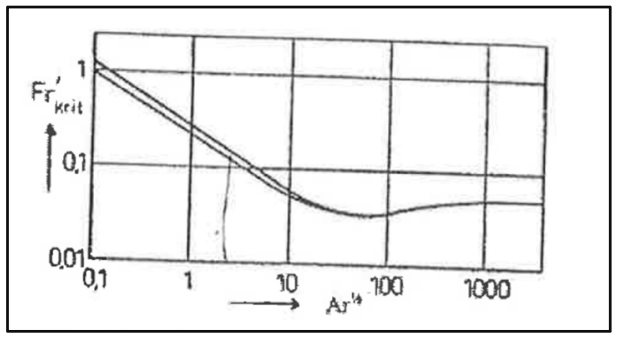

Figure 10: Critical densimetric Froude Number for bed movement as function of the Archimedes number [15]. 


\subsubsection{Moving bed to asymmetric suspension}

For transition between the moving bed and asymmetric suspension (heterogeneous) flow regime, Darby [2] mentioned several correlations and based on the work of Newitt [3] it is defined as

$$
\mathrm{v}_{3}=17 \mathrm{v}_{\mathrm{t}}
$$

where $\mathrm{v}_{\mathrm{t}}$ is the terminal/settling velocity given by

$$
\begin{gathered}
\mathrm{v}_{\mathrm{t}}=\sqrt{\left(\frac{4\left(\rho_{\mathrm{s}}-\rho_{\mathrm{l}}\right) \mathrm{gd}}{3 \rho \mathrm{C}_{\mathrm{D}}}\right)}, \\
\mathrm{C}_{\mathrm{D}}=\frac{24}{\operatorname{Re}_{\mathrm{dp}}}+0.44 \\
\operatorname{Re}_{\mathrm{dp}}=\frac{\rho_{\mathrm{l}} \mathrm{v}_{\mathrm{l}} \mathrm{dp}}{\mu_{\mathrm{l}}}
\end{gathered}
$$

$C_{D}$ is the drag coefficient and $R_{d p}$ is Reynolds number based on the particle size. The $\mathrm{V}_{3}$ has been calculated by a numerical iterative procedure. It is based on the liquid properties and particle characteristics.

\subsubsection{Asymmetric suspension to symmetric suspension}

Transition between the asymmetric (heterogeneous) and symmetric (homogeneous) flow regime is characterised by a critical velocity $[2,3]$

$$
\mathrm{V}_{4}=38.7\left(\mathrm{gDv}_{\mathrm{t}}\right)^{0.33}
$$

The $\mathrm{V}_{4}$ has been calculated by a numerical iterative procedure. It is based on the liquid properties and particle characteristics.

Based on the above calculated transition velocities and for a given operating mixture velocity $\left(\mathrm{V}_{\mathrm{m}}\right)$ flow regime can be predicted as:

For $\mathbf{V m}<\mathbf{V}_{\mathbf{2}}: \quad$ Stationary bed flow regime. In the lower part of the pipe a stationary bed exists and in the upper part of the pipe particles move by saltation.

For $\mathbf{V}_{\mathbf{2}}<\mathbf{V m}_{\mathbf{m}}<\mathbf{V}_{\mathbf{3}}$ : $\quad$ Moving bed flow regime. In the lower part of the pipe moving bed particles exists and in the upper part of the pipe some particles move by saltation or some by suspension.

For $\mathbf{V}_{\mathbf{3}}<\mathbf{V m}<\mathbf{V}_{\mathbf{4}}$ : Asymmetric suspension or heterogeneous flow regime. Mixture flows in the asymmetric suspension, the velocity below which solid form a deposit on the bottom of pipe. This flow regime occurs in most of the practical applications.

For $\mathbf{V m}>\mathbf{V}_{\mathbf{4}}$ : $\quad$ Symmetric suspension or homogenous flow regime. Mixture flows in the symmetric suspension. This operating velocity is very difficult to achieve.

The flow regime maps can be constructed based on the particle diameter and transition velocities calculated by equations (3) to (11) and are presented in Figure 11. CFD calculated cases are also shown in Figure 11. Empirical models are unreliable near the transition flow regimes. The legend of the CFD predicted 


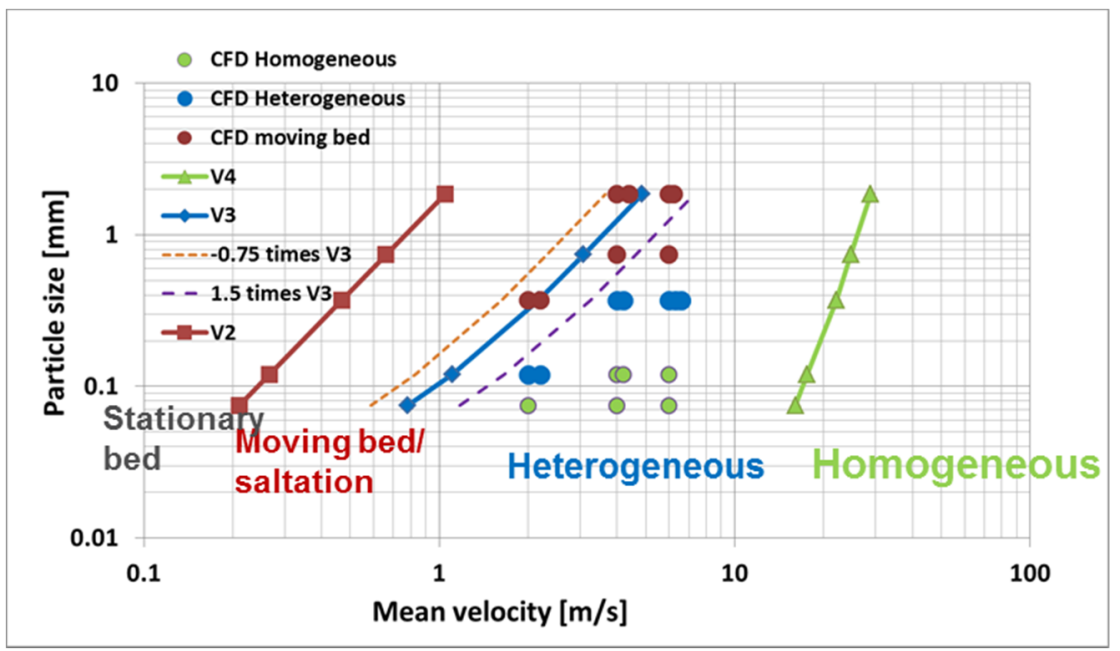

Figure 11: Flow regimes based on the empirical models and CFD simulation points.

flow regimes are assigned as circles with different colours. The red coloured circles for the moving bed, the blue coloured circles for heterogeneous regime and the green circles for homogenous regime respectively. Empirical transition velocities are assigned with continuous line legends (with filled marker symbols).

- $\quad$ For the higher particle sizes $\left(d_{50}\right.$ of $0.74 \mathrm{~mm}$ at $V_{m}$ of 4 or $6 \mathrm{~m} / \mathrm{s}$ and $d_{50}$ of $1.85 \mathrm{~mm}$ at $\mathrm{V}_{\mathrm{m}}$ of $6 \mathrm{~m} / \mathrm{s}$ ) CFD predicts the moving bed flow regime whereas empirical correlations still predicts heterogeneous flow.

For the small particles $\left(\mathrm{d}_{50}<0.12 \mathrm{~mm}\right)$ CFD predicts the homogeneous flow regime whereas empirical correlations predict heterogeneous flow.

\section{Conclusions}

The following conclusions have been drawn on the basis of the present investigation:

1. The Eulerian-granular model was successfully used and is capable of predicting the solid concentration, pressure drop and flow regimes.

2. For the larger particles, calculated flow regimes were either strongly heterogeneous or moving bed flow regimes.

3. For very low flow rates $\left(\mathrm{V}_{\mathrm{m}}<2 \mathrm{~m} / \mathrm{s}\right)$ or very large particle sizes, the CFD results deviated from the experimental data.

4. The solid concentration distribution and pressure drop obtained by the CFD simulations were found to be in good agreement with the experimental data. 
5. Flow regimes calculated based on the CFD simulations were compared with the empirical equations. The flow regimes calculated from empirical equations near the transition velocities are unreliable. The CFD simulations provide better results.

\section{References}

[1] Duarnd, R., Proceedings of Minn. Hydraulic Convention, 1953.

[2] Darby, R., Hydrodynamics of slurry and suspensions, N.P. Cheremisinoff (ed), Encyclopaedia of Fluid Mechanics, vol. 5: Slurry Flow Technology, Gulf Publishing Company, Houston, 1986.

[3] Newitt D.M, Trans. Inst. Chem. Engineers., 33, 93, 1955.

[4] Kaushal, D.R., Thinglas, T., Tomita, Y., Kuchii, S., Tsukamoto, H., CFD modelling for pipeline flow of particles at high concentration. International Journal of Multiphase Flow, 43, pp. 85-100, 2012.

[5] Ling. J., Skudarnov. P.V., Lin. C.X., \& Ebadian. M. A., Numerical investigations of liquid-solid slurry flows in a fully developed turbulent region. International Journal of Heat and Fluid Flow, 24, pp. 389-398, 2003.

[6] Kaushal, D.R., \& Tomita, Y., Experimental investigation of near-wall lift of coarser particles in slurry pipeline using gamma-ray densitometer. Powder Technology, 172, pp. 177-187, 2007.

[7] Eesa, M., \& Barigou, M., CFD investigation of the pipe transport of coarse solids in laminar power law fluids. Chemical Engineering Science, 64, pp. 322-333, 2009.

[8] Wood, R.J.K, Jones, .F., Ganeshalingam, J., \& Miles, N.J., Comparison of predicted and experimental erosion estimated in slurry ducts, Wear, 256, pp. 937-947, 2004.

[9] Matousek, v., Pressure drops and flow patterns in sand-mixture pipes. Experimental Thermal and Fluid Science, 26, pp. 693-702, 2002.

[10] Giguere, R., Fradette, L., Mignon, D., \& Tanguy, P.A., Characterization of slurry flow regime transitions by ERT, Chemical Engineering Research and Design, 86, pp. 989-996, 2008.

[11] Faraj, Y., \& Wang., ERT investigation on horizontal and vertical countergravity slurry flow in pipelines, Procedia Engineering, 42, pp. 588-606, 2012.

[12] Marousek, V., Krupicka, J., \& Tomas, Picek, Validation of transport and friction formulae for upper plane bed by experiments in rectangular pipe, J. Hydrol. Hydromech. 61 (2), pp. 120-125, 2013.

[13] ANSYS, Inc. ANSYS Fluent 12. Theory Guide, April 2009.

[14] Deewanji, T.S., O’Mahoney, T.S., \& Twerda, A., Numerical Investigation of Particle Deposition in Oscillatory Baffled Reactors, $23^{\text {rd }}$ International Symposium on Transport Phenomena, Auckland, New Zealand, 19-22 November 2012.

[15] Yalim, M.S., Mechanics of sediment transport, $2^{\text {nd }}$ edition, Pergamon Press, Oxford, 1977. 